\title{
Correction to: Innovators' Acts of Framing and Audiences' Structural Characteristics in Novelty Recognition
}

\author{
Gino Cattani, Denise Falchetti and Simone Ferriani
}

\section{Correction to:}

Chapter 2 in: J. Strandgaard Pedersen et al. (eds.), Technology and Creativity, https://doi.org/10.1007/978-3-030-17566-5_2

The original version of the chapter was inadvertently published without the additional Acknowledgements content regarding the study in Chapter 2, which has now been included. The chapter has been updated with the necessary change. 